Казаков Л. О. *

\title{
ПЕРСПЕКТИВЫ РАЗВИТИЯ МАЛОГО \\ И СРЕДНЕГО БИЗНЕСА В АФГАНИСТАНЕ
}

\author{
Kazakov Lev** \\ PERSPECTIVES OF SMALL AND MEDIUM \\ ENTERPRISES DEVELOPMENT IN AFGHANISTAN
}

DOI: 10.31696/2227-5568-2020-02-047-059

\begin{abstract}
Аннотация: Малый и средний бизнес в Афганистане может стать главным источником экономического развития страны. К этому в значительной степени располагает сложившаяся в ИРА политическая и экономическая ситуация: в условиях резкого сокращения объемов международной помощи, а также возможного обострения проблемы безопасности в связи с планируемым выводом основной части контингента иностранных войск из Афганистана руководству страны придется решать проблему поиска альтернативных внутренних источников развития экономики с целью достижения большей самостоятельности. Более того, развитие малого и среднего бизнеса представляет собой одно из наиболее перспективных практически реализуемых направлений экономической политики государства: предприятия данного масштаба способны выживать в условиях продолжающегося на территории Афганистана вооруженного конфликта; благодаря ним обеспечивается большая часть внешней торговли страны. Успех реализации перспектив расширения малых и средних предприятий будет напрямую и в наибольшей степени зависеть от мер, предпринимаемых правительством ИРА в политической и экономической области, сфере безопасности. Не менее важным станет внешнеторговый аспект, предполагающий выстраивание курса на более тесное сотрудничество с государствами региона. В настоящей статье анализируется современное состояние частного сектора Афганистана, приводится обоснование приоритетности поддержки малых и средних предприятий, рассматриваются стоящие перед ними вызовы. Помимо этого, автор ставит своей целью определить основные направления деятельности правительства ИРА в целях реализации перспектив развития малого и среднего бизнеса. В данном контексте подробно рассматриваются дальнейшие меры руководства страны в различных областях, в частности, облегчение условий ведения бизнеса, разрешение проблемы политической нестабильности, совершенствование системы таможенного контроля, пересмотр роли Афганистана в региональной торговле.
\end{abstract}

Ключевые слова: бизнес в Афганистане, CASA-1000, малые и средние предприятия, отчет «Doing Business».

Abstract: Small and medium enterprises in Afghanistan may become the main source of the country's economic development. Afghanistan's current political and economic background is what contributes a lot to such a change: with international aid at a sharp

\footnotetext{
* Казаков Лев Олегович - студент МГИМО МИД России; e-mail: kazakov.lev.2017@yandex.ru. ORDCID: 0000-0002-6845-1954

*** Lev O. Kazakov - student of MGIMO University; e-mail: kazakov.lev.2017@yandex.ru.
} 
decline and security problem being likely to worsen due to the anticipated withdrawal of the major part of international forces from Afghanistan, the government faces a problem of finding alternative sources of economic development within the country with the aim of achieving further self-sufficiency. Besides, support for SMEs is by far the most practically achievable and promising goal on the government's economic agenda: those enterprises are capable of surviving within the ongoing military conflict; SMEs contribute to the conduct of most Afghan trade. Further advance of the abovementioned is directly and particularly dependent on the Afghan government's political and economic action, as well as the undertaking of security measures. Afghanistan's international trade is another critical aspect, which suggests that the country is yet to establish closer economic ties with other regional states. The article analyses the country's private sector, suggests an explanation of why the SMEs' advance should have primacy over other enterprises, and discusses the challenges faced by SMEs in Afghanistan. Besides, the author is determined to identify the main courses of action the Afghan government should stick to so as to achieve the realization of the SMEs' perspectives. In the context the author dwells on the government's further steps in various spheres, namely, improving ease of doing business, dealing with the problem of political uncertainty, enhancing the system of customs control, revising of Afghanistan's role within regional trade.

Key words: business in Afghanistan, CASA-1000, small and medium enterprises, Doing Business Report.

В октябре 2017 г. Всемирным Банком был опубликован ежегодный отчет «Doing Business». Помимо основного доклада организация представила результаты ряда региональных, внутригосударственных, тематических и иных исследований, среди которых впервые со времени составления доклада (2003 г.) была рассмотрена Исламская Республика Афганистан. Особенностью отчета стали его субнациональный характер, означающий сравнение отдельных регионов страны (в данном случае - пяти афганских провинций: Балх, Герат, Кабул, Кандагар, Нангархар) по определенным критериям как между собой, так и с отдельными районами в других государствах. В случае применения эффективных рецептов, описанных в докладе, Афганистан, по мнению экспертов, значительно улучшит законодательство в области регулирования бизнеса и поднимется на 172 строчку (на 11 позиций) в рейтинге «Doing Business».

Насколько актуальны рекомендации по облегчению ведения бизнеса для страны, которая находится в условиях многолетнего военного конфликта, угнетающего ее экономику? Исследователи и эксперты сходятся во мнении о том, что правительству Исламской Республики необходимо пересмотреть экономическую стратегию страны, уделив при этом особое внимание поиску новых источников развития. С этой точки зрения, международная помощь, объемы которой неуклонно сокращаются с 2012 г., по всей видимости, в обозримом будущем отойдет на второй план: старту новых проектов на территории страны, очевидно, препятствует 
продолжающийся вооруженный конфликт, с чем связана невозможность предоставить инвесторам гарантии безопасности в реализации их идей. Кроме того, крупные проекты, начало осуществления которых подтверждено и согласовано, в сущности, находятся в «замороженном» состоянии, поскольку их фактическая реализация всякий раз переносится на неопределенный срок: ярким примером может служить энергетический проект CASA-1000 (Центральная Азия - Южная Азия), о старте которого было официально объявлено сначала в мае 2016 г., ${ }^{1}$ а затем повторно в феврале 2020 г. $^{2}$; реализация CASA-1000, таким образом, была отложена минимум на 2-3 года.

Основным и более эффективным источником развития страны видится афганский частный сектор. По данным Всемирного Банка ${ }^{3}$, к 2017 г. частный сектор экономики Афганистана оставался весьма ограниченным: в нем было занято около 50\% населения страны; объем кредитов, предоставленных частному сектору, не превышал 4\% ВВП, что значительно ниже по сравнению со средним показателем среди стран с низким уровнем дохода - 28\% ВВП; объем совокупных капиталовложений в частный сектор составил 5,9\% ВВП. По мнению исследователей, снижение ограничений, которыми связан афганский частный сектор, имеет ключевое значение с точки зрения обеспечения устойчивого развития в долгосрочной перспективе - разумеется, наряду с урегулированием политической нестабильности, разрешением проблем безопасности, коррумпированности государственных структур, а также нехватки опытных работников, оговариваются эксперты.

В одной из статей, опубликованных на сайте «Афганистан.Ру» ${ }^{4}$, аналитики интернет-ресурса в продолжение данной темы делают акцент на преимуществах малого и - в меньшей степени - среднего бизнеса в афганском частном секторе. Малый бизнес (от 10 до 100 работников, выручка - до 1 млн долл. уставный капитал - до 1 млн долл. как правило, индивидуальный, с весьма ограниченными основными фондами (здания, сооружения, средства производства, оборотные капиталы и т.д.), становится, вопреки расхожему мнению, не жертвой войны, а наиболее живучим видом бизнеса по сравнению со средним (от 100 до 500 работников) и крупным (что касается него, то эксперты выразили сомнения относительно реальных перспектив его развития в Афганистане). Этому

\footnotetext{
${ }^{1}$ Casa-1000 Formally Inaugurated. 16.05.2016. URL: https://dailytimes.com.pk/81955/ casa-1000-formally-inaugurated/ (дата обращения: 07.06.2020).

2 Afghan Leader Inaugurates Construction of Key Regional Energy Project. URL: https://www.voanews. com/south-central-asia/afghan-leader-inaugurates-construction-key-regional-energy-project (дата обращения: 07.06.2020).

3 Doing Business in Afghanistan 2017, p. 14. URL: https://www.doingbusiness.org/content/dam/ doingBusiness/media/Subnational-Reports/DB17-sub-afghanistan.PDF (дата обращения: 12.04.2020). 4 «Малый бизнес восстановит Афганистан». URL: http://afghanistan.ru/doc/112440.html (Опубликовано: 21.07.2017 21:20) (дата обращения: 03.05.2020).
} 
способствует, в частности, то, что небольшие размеры основных фондов предприятий малого бизнеса позволяют в случае опасности оставить их и впоследствии начать дело заново.

Аналитики «Афганистан.Ру» в свою очередь также выступают за снижение ограничений в отношении афганского малого и среднего бизнеса. По их мнению, руководители даже самых мелких предприятий должны сконцентрироваться на накоплении прибыли компаний, поскольку объем накоплений в значительной степени влияет на возможности афганского бизнеса в целом, а также и на финансовые возможности государства. Поэтому, считают авторы, существует реальная возможность возложить задачу по повышению национального благосостояния на малый и средний бизнес.

\section{Современное состояние частного сектора в ИРА}

С 2001 г. по настоящее время в Афганистане продолжается процесс политической и экономической реконструкции. Как представляется, дать однозначную оценку этим изменениям весьма трудно. Отстранение от центральной власти представителей движения «Талибан» в 2001 г., последовавшие за этим переходный период, провозглашение Исламской Республики Афганистан, создание постоянного правительства, а также принятие основного закона страны, безусловно, стали важными вехами в ходе становления новой политической системы Афганистана. Однако обеспечение легитимности и номинального признания центральной власти, между тем, отнюдь не означало установление политической стабильности в Афганистане. Несмотря на значительные успехи в деле борьбы с террористическими группировками, действующими на территории ИРА, окончательно избавить страну от влияния экстремистов не удалось: боевики продолжали контролировать отдельные уезды или даже провинции Афганистана, в особенности, наиболее отдаленные от центра. Продолжение на территории страны военных операций США и НАТО с одной стороны оставалось сдерживающим фактором для дальнейшего распространения власти представителей террористических организаций, с другой - требовало задействования все больших сил и средств, результатом чего стало увеличение численности иностранных военнослужащих (пик был достигнут в 2009-2010 гг.), последовавшее усиление боевых действий и дальнейший рост числа жертв среди гражданского населения: с 6000 в 2009 г. до почти 8000 в 2011 г. ${ }^{5}$ Кроме того, военная кампания США и НАТО в Афганистане все чаще стала характеризоваться как «затянувшаяся» и «ресурсоемкая», что в конце концов обусловило начало,

${ }^{5}$ Afghanistan to 2030: priorities for economic development under fragility, p. 11. URL: http://documents. worldbank.org/curated/en/156881533220723730/pdf/129161-WP-P157288-Afghanistan-to-2030PUBLIC.pdf (дата обращения: 12.04.2020). 
к слову, не менее затянувшегося (с 2010 г.) вывода американских и международных войск.

В экономической сфере заметны позитивные изменения. За 15 лет со времени свержения режима талибов (по данным на 2016 г.) Афганистану удалось улучшить свои позиции по ряду показателей: ВВП на душу населения вырос со 120 до 580 долларов, средняя продолжительность жизни увеличилась в полтора раза и составила 61 год, значительно сократилась смертность женщин во время родов - с 1,600 до 327 случаев (в расчете на каждые 100,000 родов), численность лиц, посещающих школы, увеличилась с 0,8 до 8 миллионов ${ }^{6}$.

Экономический рост, наметившийся в 2007-2008 гг., служил лишь малозначимым с точки зрения разрешения основных социальноэкономических проблем Афганистана фоном, на котором ввиду сохранявшегося военного конфликта продолжали усиливаться основные неблагоприятные тенденции: резкое повышение уровня бедности в сельских районах ${ }^{7}$, постепенно дополнявшее его повышение уровня бедности городского населения, усиление социального неравенства. Экономика Афганистана по-прежнему не предоставляла достаточно рабочих мест, что также снижало положительный эффект от экономического роста. В результате этого стала очевидной невозможность решить основные социально-экономические проблемы страны, прежде всего проблему бедного населения, лишь добившись роста экономики.

Как было отмечено ранее, в 2010 г. начался постепенный вывод иностранных войск из ИРА. По мере сокращения численности международного контингента снижался уровень безопасности в стране в связи с заполнением «вакуума силы» террористическими организациями, ведущими свою деятельность на территории Афганистана. В результате этого снижались также и объемы международной помощи, которую предполагалось направить на гражданские и военные нужды. Осложнение ситуации с безопасностью, сокращение внешней помощи и политическая нестабильность привели к резкому сокращению совокупного спроса в стране. Негативное влияние данных факторов усилилось в связи с неблагоприятными климатическими условиями и сокращением сельскохозяйственного производства. Ответом на возросший уровень насилия в Афганистане стало увеличение внутренних расходов на обеспечение безопасности. Государственные резервы оказались истощены в связи с сохраняющимся уровнем коррупции, а также - в большей степени - мировым финансовым кризисом 2008-2009 гг.

Негативные тенденции, проявившиеся в первую очередь в экономике страны, оказали отрицательное влияние и на состояние частного сектора.

\footnotetext{
${ }^{6}$ Afghanistan to 2030: priorities for economic development under fragility. P. 9.

7 Afghanistan Living Conditions Survey 2016-17. URL: https://reliefweb.int/sites/reliefweb.int/files/ resources/alcs_2017.pdf (дата обращения 17.05.2020).
} 
Так, за период 2012-2016 гг. число регистрируемых предприятий сократилось более чем вдвое; объем кредитов, предоставляемых коммерческими банками предприятиям частного сектора, снизился с 4,9\% ВВП в 2011 г. до 3,4\% ВВП в 2016 г., повысилась ликвидность банков, что говорит о снижении спроса на кредит; деятельность крупных предприятий горнодобывающей отрасли была приостановлена правительством в связи с возросшими административными рисками.

Другим фактором, негативно повлиявшим на афганский частный сектор в последние несколько лет, стала проблема перемещенных лиц. Численность как внутренних, так и внешних перемещенных лиц возросла, составив (по состоянию на 2016 г.) 1,2 и 1 миллион человек соответственно. В связи с тем, что смена указанными лицами места постоянного проживания по самой сути понятия является вынужденной, с точки зрения экономики, такой приток населения сопряжен с дополнительными проблемами, связанными с предполагаемым низким уровнем совокупных знаний, умений и навыков у данных лиц, а также небольшим объемом располагаемых ресурсов. В тех районах страны, где было зарегистрировано наибольшее количество перемещенных лиц, наблюдается более высокая конфликтность, что связано с возросшим в результате притока населения спросом на землю и другие ресурсы.

\section{Вызовы малому и среднему бизнесу в Афганистане}

Основным вызовом малому и среднему бизнесу стало отсутствие общей стратегии развития малых и средних предприятий на начальном этапе становления Исламской Республики. Только в 2009 г. было объявлено об окончании разработки стратегии, практическое применение которой началось не ранее 2011 г., когда в структуре Министерства торговли и промышленности было учреждено Управление по развитию предприятий малого и среднего бизнеса ${ }^{8}$. Ввиду значительного торгового дефицита был сделан акцент на развитии импортозамещающих отраслей. Так, Управление занималось сбором информации о состоянии рынка, а также привлечением помощи со стороны государства и доноров с целью повышения производства ключевой продукции - продуктов питания, овощей, масла, молочных продуктов. В связи с ограниченностью экспорта Афганистана традиционными для этой страны видами продукции данное направление не получило развития в стратегии. Зависимость мероприятий, осуществляемых в рамках стратегии развития малых и средних предприятий, от иностранной помощи стала причиной чрезмерной ориентации предпринимателей на внешнюю финансовую

\footnotetext{
${ }^{8}$ Small and Medium Enterprises Development and Regional Trade in Afghanistan, p. 8. URL: https:// www.ucentralasia.org/Content/downloads/UCA-IPPA-WP24-Eng.pdf (дата обращения: 03.05.2020).
} 
поддержку, что в конечном счете ограничило самостоятельность и возможности расширения компаний малого и среднего бизнеса в долгосрочной перспективе. Донорские организации, в частности, Агентство США по международному развитию, занимавшиеся финансированием проекта развития малых и средних предприятий, попытались заменить недостающие звенья в цепочках стоимости, создание которых так и не увенчалось успехом.

Говоря об экспорте, необходимо упомянуть проблему доступа предприятий малого и среднего бизнеса на внешний рынок. Наиболее уверенные (или наименее подверженные опасности) позиции здесь занимают предприятия, давно вышедшие на рынок, которым за последние двадцать лет удалось восстановить и расширить свои коммерческие связи. К таковым можно отнести, в частности, предприятия, занимающиеся экспортом сухофруктов. Более мелким компаниям значительно труднее получить доступ к рынку. Обычной практикой в данной сфере является проведение за рубежом сельскохозяйственных выставок, призванных помочь предприятиям в реализации продукции. Однако, как правило, владельцы компаний не рассматривают их как возможность установления долгосрочных торговых отношений.

Другим препятствием на пути развития предприятий малого и среднего бизнеса стало отсутствие у афганских предпринимателей реальных стимулов к законному оформлению своих компаний. Около 70-80\% малых и средних предприятий в Афганистане не прошли процедуры регистрации и осуществляют свою деятельность неофициально. Стимулы в данном случае как раз обратные: владельцы бизнеса стремятся избежать ненужной бюрократии и ограничить риск пострадать от коррумпированности государственных структур, взаимодействие с которыми неизбежно в случае официальной регистрации предприятия. В то же время такие компании лишаются возможных перспектив защиты и поддержки со стороны государства, подвергая себя другой опасности - попадания под покровительство и в зависимость от криминальных объединений. Закономерным результатом становится снижение качества производимых товаров и, как следствие, сокращение доходов государства.

Еще одним вызовом афганскому частному сектору является создание более четких и понятных «правил игры» на рынке. Так, основа рекомендаций экспертов исследования «Doing Business» по данному вопросу - представление о том, что существование именно таких правил в наибольшей степени способствует развитию частного сектора любого государства 9 Законодательство, таким образом, должно закреплять и обеспечивать право собственности, способствовать скорейшему разрешению споров, повышению предсказуемости экономических отношений, а также

9 Doing Business in Afghanistan 2017. P. 14. 
гарантировать предприятиям защиту от произвола и злоупотреблений. Правила должны быть понятны, прозрачны и доступны к реальному соблюдению теми, чьи экономические отношения они регулируют. На сегодняшний день экспертами были предложены многочисленные рекомендации по изменению законодательства в области регулирования деятельности предприятий частного сектора. Это говорит о том, что, по мнению исследователей, «условия игры», созданные в Афганистане, требуют значительной корректировки. Так, сегодня Афганистан занимает 173 позицию (из 190) в рейтинге легкости ведения бизнеса. Число необходимых процедур, предшествующих регистрации предприятия и началу его официальной деятельности, а также затраты времени на их прохождение, по сравнению с государствами-лидерами рейтинга, в ИРА значительно больше: в частности, в Новой Зеландии получение разрешения на строительство получают при прохождении 11 процедур, что занимает 93 дня, в то время как в Афганистане данный процесс включает 13 процедур в провинции Кабул, 14-в провинции Балх, 23 - в провинции Герат и укладывается в 356, 108 и 133 дней соответственно. На регистрацию собственности у новозеландских предпринимателей уходит 3.5 дня, а у афганских - 250 в провинции Кабул, 119 - в провинции Балх, 236 - в провинции Герат. Помимо этого, ведение бизнеса осложняется спецификой общественных отношений в Афганистане. Это, в частности, весьма актуально для женщин, стремящихся открыть свое предприятие, поскольку замужней женщине необходимо получить разрешение супруга на то, чтобы заняться бизнесом, иначе, согласно Гражданскому кодексу Афганистана 1977 г., она может лишиться права на обеспечение со стороны мужа в связи с тем, что покинула место проживания без согласия супруга.

\section{Перспективы развития малых и средних предприятий}

Разрешение упомянутых выше проблем требует комплексного подхода, включающего преобразования в экономической, политической и правовой сферах, а также системе безопасности. В частности, следует обратить внимание на развитие частного сектора, совершенствование законодательства в области ведения бизнеса, принятие мер политического характера в целях защиты малых и средних предприятий от последствий политической нестабильности, а также поощрение внешней торговли.

Важную роль в развитии частного сектора призвана сыграть Государственная программа приоритетов развития частного сектора, рассчитанная на 2018-2023 гг. ${ }^{10}$ В 2018 г. Правительство национального единства

10 Private Sector Development, National Priority Program (NPP), 2018-2023. URL: http://policymof. gov.af/home/wp-content/uploads/2019/01/Private-Sector-Development-NPP.pdf (дата обращения: 09.05.2020). 
определило четыре приоритетных направления развития частного сектора Афганистана, которые были впоследствии закреплены в упомянутом документе: создание благоприятной среды для коммерческой деятельности, упрощение доступа к источникам финансирования бизнеса, оценка возможностей и необходимости инвестирования, обеспечение и поощрение внешней торговли и транзита через Афганистан.

В связи с необходимостью принятия мер также и политического характера основной задачей является снижение рисков для малых и средних предприятий понести убытки в связи с последствиями политической нестабильности и высоким уровнем преступности в ИРА.

Согласно имеющимся данным ${ }^{11}, 15,5 \%$ всех предприятий в Афганистане наносится ущерб в связи с деятельностью преступных группировок. Наибольшие убытки несут предприятия среднего бизнеса, они же более подвержены именно этому риску, чем малые или крупные предприятия: представляя удобную цель для преступников, средние предприятия не имеют достаточно возможностей для защиты.

Эксперты отмечают, что суть проблемы политической нестабильности в Афганистане состоит не столько в несоблюдении законодательства, сколько в непредсказуемости и конфликтности, вызванной тем, что различные политические силы не стремятся не только соблюдать, но и устанавливать «правила игры». В результате вольного, неоднозначного правоприменения подрывается легитимность официальной власти, снижается доверие со стороны инвесторов.

Экономико-правовой аспект имеет важное значение с точки зрения расширения равных, обеспеченных законом возможностей для осуществления экономической деятельности, однако, как свидетельствует международный опыт, экономическая мотивация далеко не всегда является решающей в вопросе участия людей в деятельности преступных объединений или вступления в повстанческие группировки. Гораздо более сильными становятся идеологические мотивы, важную роль играют этнические противоречия, которые зачастую поддерживаются самим государством. Таким образом, задача правительства заключается в проведении фундаментальных институциональных реформ с целью создания системы, в которой будут защищены и обеспечены интересы различных групп населения, в том числе с учетом их этнической принадлежности и национального самосознания.

Другим важным направлением развития малых и средних предприятий в Афганистане является развитие внешней торговли. Актуальность данной задачи обусловлена тем, что большая часть внешней торговли ИРА (за исключением импорта электроэнергии, который осуществляется государством или крупными компаниями) обеспечивается малыми

${ }^{11}$ Afghanistan to 2030: priorities for economic development under fragility. P. 38. 
и средними предприятиями ${ }^{12}$. Мероприятия в данной области должны быть направлены на разрешение трех основных проблем: нестабильной ситуации с системой безопасности Афганистана; трансграничного контроля и таможенных технологий; ограниченности инфраструктуры. Поскольку вопросы безопасности уже были рассмотрены ранее, следует остановиться на проблемах трансграничного контроля и таможенных технологий, а также ограниченности современной инфраструктуры.

Осуществление таможенного контроля при пересечении афганскими товарами границ государств Центральной Азии, как правило, сопровождается недоверием местных компетентных органов к добросовестности афганских поставщиков, которые нередко подозреваются в перевозке «наркотиков и оружия» ${ }^{13}$. С этим связаны частые досмотры грузов из Афганистана, что не может не осложнять взаимную торговлю. Дальнейшего совершенствования требует Автоматизированная система обработки таможенных данных, разработанная Конференцией Организации Объединенных Наций по торговле и развитию и продемонстрировавшая свою эффективность в Афганистане. Центральноазиатские партнеры ИРА еще не освоили данную технологию либо не обеспечили достаточно широкого ее применения, что власти страны связывают с «нехваткой веры [государств Центральной Азии] в увеличение объемов торговли» ${ }^{14}$ с Афганистаном. Между тем преимуществом системы является оперативное обеспечение обмена информацией, касающейся прямых или транзитных перевозок, между таможенными пунктами как внутри страны, так и с соответствующими учреждениями за рубежом.

В связи с недостаточной развитостью инфраструктуры и высокой стоимостью сухопутных перевозок межрегиональная торговля государств Центральной и Южной Азии до сих пор находится на весьма низком уровне (значительно ниже межрегиональной торговли в Африке, Латинской Америке, Юго-Восточной Азии и на Ближнем Востоке), и составляет от 0,2 до 4\% общего объема торговли по всем направлениям ${ }^{15}$. Как представляется, Афганистан может сыграть важную роль в развитии данного торгового направления не только в качестве государства, обеспечивающего транзит между Центральной и Южной Азией, но и как возможный партнер Индии, которая реализует свою продукцию на европейских рынках путем поставок через центральноазиатские республики. Помимо этого, государства Центральной Азии могут стать более надежными торговыми партнерами Афганистана: в Пакистане - одном из главных торговых партнеров Афганистана - по-прежнему не урегулированы проблемы

\footnotetext{
${ }^{12}$ Small and Medium Enterprises Development and Regional Trade in Afghanistan. P. 20.

13 Ibid. P. 16

14 Ibid.

15 Munich Personal RePEc Archive, Regional Economic Integration in Central Asia and South Asia (2015) URL: https://mpra.ub.uni-muenchen.de/66436/ (дата обращения: 17.05.2020).
} 
приграничной и общей безопасности, что препятствует поддержанию торговли между двумя государствами. По мнению экспертов, в данной ситуации ИРА не стоит рассчитывать лишь на развитие торговых отношений с соседями - более эффективной стратегией представляется развитие роли Афганистана как транзитного коридора для движения иностранных товаров.

Реализация перспектив дальнейшего развития предприятий малого и среднего бизнеса в Афганистане напрямую и в наибольшей степени зависит от государства. С 2014 г. кабинету Ашрафа Гани удалось достичь успехов в разрешении, в первую очередь, общих проблем в политической и социально-экономической сферах, а также в частности, создать механизм выявления коррупционного поведения, улучшить предпринимательский климат в стране, повысить уровень доверия инвесторов, внедрить автоматизированные системы, облегчающие задачи по контролю над торговыми операциями между Афганистаном и государствамипартнерами. Тем временем показатели по результатам работы на основных направлениях, по всей видимости, ухудшаются: располагаясь в течение двух лет (2016-2017) на 183 строчке в рейтинге легкости ведения бизнеса, Афганистан в 2019 г. опустился до 173 позиции, что говорит о происходящем в стране еще большем ужесточении законодательства для предпринимателей ${ }^{16}$; индекс коррупции сохранился на прежнем уровне - 16, по данным Transparency International ${ }^{17}$. Перед нынешней администрацией Гани проблема поиска новых источников развития стоит гораздо более серьезно: значительному усилению противоречий между основными претендентами на власть в Афганистане способствовал кризис президентских выборов конца 2019 г., окончательно разрешить который до сих пор не удается; на фоне вновь обострившегося в ИРА кризиса власти основной донор - США - заявили о снижении на 1 млрд долл. помощи, предоставляемой Афганистану.

Предпринимательская активность в Афганистане, тем не менее, сохраняется, продолжая играть важную роль в повышении национального благосостояния. Позитивным примером может служить среднее предприятие с весьма символичным названием «Табассум» (улыбка - перс.), действующее в Кабуле с 2007 г. и занимающееся производством и экспортом изюма ${ }^{18}$. Около 110 постоянных сотрудников предприятия обеспечивают ежегодный экспорт 3000-4000 т изюма в государства Центральной Азии и затем в Европу и Северную Америку. 40\% рабочих «Табассум»женщины. Компания сотрудничает с домашними хозяйствами и другими фирмами, закупая свежий виноград. «Табассум» продолжает свою

\footnotetext{
16 Trading Economics, Afghanistan - Economic Indicators. URL: https://tradingeconomics.com/ afghanistan/indicators (дата обращения: 17.05.2020).

17 Ibid.

${ }_{18}$ Small and Medium Enterprises ... P. 18
} 
деятельность несмотря на частые проблемы, вызывающие спад производства и потерю зарубежных партнеров. В 2014 г. более половины продукции, направленной компанией на экспорт, было задержано во время транзита через Узбекистан в связи с тем, что власти страны предоставили приоритетное право провоза грузов из Пакистана. В результате товар «Табассум» поступил заказчику значительно позже оговоренного срока, что подорвало отношения с зарубежным партнером - срок годности продукции афганского производства оказался истекшим.

Таким образом, помимо проведения внутреннего курса на развитие предприятий малого и среднего бизнеса, правительству ИРА необходимо уделить внимание внешнеполитическому аспекту данной задачи. Развитие потенциала и перспектив малого и среднего бизнеса в Афганистане, а следовательно, и освоения нового, внутреннего источника развития национальной экономики, невозможно без улучшения климата в отношениях между Афганистаном и его политическими и торговыми партнерами. Достижение этой цели, по всей вероятности, откладывается на неопределенный срок, в течение которого президентский дворец «Арг» и оплот оппозиции «Сэпидар» будут пытаться разрешить противоречия и приступить к осуществлению единой экономической политики в интересах государства.

\section{Электронные ресурсы / Electronic Sources}

1. Casa-1000 Formally Inaugurated. 16.05.2016. URL: https://dailytimes.com. pk/81955/casa-1000-formally-inaugurated/ (дата обращения: 07.06.2020).

2. Afghan Leader Inaugurates Construction of Key Regional Energy Project. URL: https://www.voanews.com/south-central-asia/afghan-leader-inauguratesconstruction-key-regional-energy-project (дата обращения: 07.06.2020).

3. Doing Business in Afghanistan 2017. URL: https://www.doingbusiness. org/content/dam/doingBusiness/media/Subnational-Reports/DB17-subafghanistan.PDF (дата обращения: 12.04.2020).

4. «Малый бизнес восстановит Афганистан». URL: http://afghanistan.ru/ doc/112440.html (Опубликовано: 21.07.2017 21:20) (дата обращения: 03.05.2020).

5. Afghanistan to 2030: priorities for economic development under fragility. URL: http://documents.worldbank.org/curated/en/156881533220723730/ pdf/129161-WP-P157288-Afghanistan-to-2030-PUBLIC.pdf (дата обращения: 12.04.2020). 
6. Afghanistan Living Conditions Survey 2016-17. URL: https://reliefweb.int/sites/ reliefweb.int/files/resources/alcs_2017.pdf (дата обращения 17.05.2020).

7. Small and Medium Enterprises Development and Regional Trade in Afghanistan. URL: https://www.ucentralasia.org/Content/downloads/UCA-IPPA-WP24-Eng. pdf (дата обращения: 03.05.2020).

8. Private Sector Development, National Priority Program (NPP), 2018-2023. URL: http://policymof.gov.af/home/wp-content/uploads/2019/01/Private-SectorDevelopment-NPP.pdf (дата обращения: 09.05.2020).

9. Munich Personal RePEc Archive, Regional Economic Integration in Central Asia and South Asia (2015). URL: https://mpra.ub.uni-muenchen.de/66436/ (дата обращения: 17.05.2020).

10. Trading Economics, Afghanistan - Economic Indicators. URL: https:// tradingeconomics.com/afghanistan/indicators (дата обращения: 17.05.2020).

11. TradingEconomics,AfghanistanCorruptionIndex.URL:https://tradingeconomics. com/afghanistan/corruption-index (дата обращения: 17.05.2020). 